\title{
COGNITIVE AND AFFECTIVE PREFERENCE OF VISUAL INFORMATION REGARDING GENDER AND LEVEL OF RESEMBLANCE OF HUMAN
}

\author{
Youngsang, Kim ${ }^{1}$, Bong Gyou, Lee ${ }^{2}$ and Hoonsik, Yoo ${ }^{3 *}$ \\ 1,2 Graduate School of Information, Yonsei University, Seoul, Korea \\ ${ }^{3}$ Convergence Business, Department of Newmedia, Seoul Media Institute of \\ Technology (SMIT), Seoul, Korea \\ *hsyoo@smit.ac.kr
}

\begin{abstract}
This research analyzes people's preferences regarding gender and level of resemblance in intelligent agents (human or companion animal forms). According to the analysis, the preferences over intelligent agent's dependent on the users' demographical characteristics (age group, gender), frequencies of driving, and uses of cars. All users of both age groups (20's and 30's) responded they prefer female intelligent agents, showing that, overall, users preferred female intelligent agents. Also, users in their 30's preferred anthropomorphic agents more so than the users in their 20's. Users responded that they drove every day or drove 5 to 6 times a week preferred anthropomorphic agents the most compared to other users. Furthermore, female users preferred anthropomorphic agents more than male users. Lastly, users who use their cars to drive to and back from work or school preferred anthropomorphic agents the most. These analyses show that there are some significant differences between different groups of various characteristics.
\end{abstract}

Keywords - intelligent agents, visual preference, companion animal intelligent agents, age groups

\section{INTRODUCTION}

An intelligent agent is a software functionality that helps users learn software like word processors and spread sheets. Originally, it was aimed to increase the productivity and efficiency of software users [1]. In the past, intelligent agent was seen as a simple assistant to increase users' efficiency. Nowadays, due to the development of service platform technology, the role of intelligent agent is broadening. Specifically, the synergy be-tween artificial intelligence and intelligent agents enabled the agents to understand and execute users' orders, showing a substantial increase in its functionality and efficiency [2].

As intelligent agent technology has been continually developing, global IT corporations have started to jump into the associated markets. As such, the market size is expected to get bigger as time passes. Along with developments such as smart homes and autonomous driving cars, intelligent agent technology will be-come more crucial [3]. Many car companies are already making strategic partnerships with ICT companies to develop intelligent agent technology, considering the technology to be a critical part of IoT business. Despite this, the role of intelligent agents in autonomous driving cars is still being debated, and has not been solidified. The current status suggests that intelligent

Received: January 3, 2019

Reviewed: March 4, 2019

Accepted: March 6, 2019

*Corresponding Author

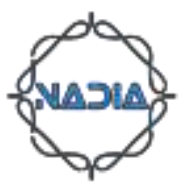


agents recognize the driver's emotions, atmosphere, and health to sense whether the driver is tired or not. If the driver is tired, the agent can recommend a break or forcefully decrease the speed, essentially lowering the chance of accidents [1].

As intelligent agents are applied to more areas and roles within cars, their functions have developed so much that they are equal to or sometimes better than humans in certain areas. Naturally, there has been debate about whether one should consider intelligent agent to be an assistant machine or a substitute for human. If one considers intelligent agents to be a substitute for personal secretaries, it is natural for one to prefer anthropomorphic, human-looking agents over others as the agents will be serving a role of a human being.

There is actual research suggesting that personified objects receive favorable evaluations compared to non-personified products or messages [4]. Not only this, the presence of a virtual personal secretary helps to build a mutual relationship between computers and humans. Furthermore, as the similarity between humans and the virtual secretary's interface increases, the trust from users also increase [5, 6]. However, as some research results show, users can show hostility towards virtual beings that are visually too real and human-like. Thus, there is definite need to consider the visual look of A.I. secretaries. The Uncanny Valley theory by Japanese roboticist Masahiro Mori introduced this idea back in 1970(Figure 1).

According to this theory, as robots look more similar to humans, the familiarity increases. But, once the look of the robots is too similar to humans, the familiarity plummets and humans start feeling uncomfortable interacting with the robots [7].

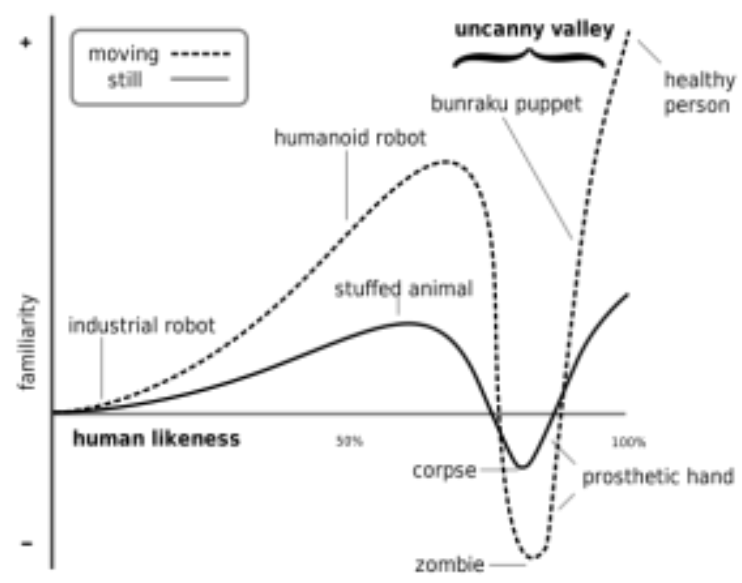

Fig. 1 Uncanny Valley Theory[8]

Uncanny Valley theory research was originally about robots, but it has been extended to virtual secretaries. According to the theory, overly similar and realistic agents received negative evaluations compared to adequately similar agents. Normal users have relatively high expectations for agents, so if anthropomorphic agents do not fulfill such expectations, users feel deep disappointments which get reflected in the negative evaluations [9]. Thus, when intelligent agents in autonomous driving cars are anthropomorphized, there will be differences between drivers' preferences over the level of anthropomorphism.

Looking at related research papers, humanoid robots with humane characteristics have great advantages in social, emotional and physical communication abilities compared to normal robots. Robots that look similar to humans tend to be evaluated to have humane personalities and psychological characteristics, and are favored more [10]. However, this kind of preference may differ depending on how to divide the users in different categories. As regards this, there has been researches carried out to compare and analyze 
the preferences towards the personified robots or AI's according to the demographic characteristics.

There are certain differences in preferences over intelligent agents depending on age groups. We analyzed a group of students between 20 years old to 39 years old and a group of elders between 61 years old to 74 years old for their preference over visuals of virtual agents. The elder group preferred human-looking virtual character while the student group did not. Elders looked at virtual secretaries as something they can talk to naturally, while students looked at them as simple machines. In addition, in regards to $2 \mathrm{D}$ and 3D characters, most students preferred 3D forms while elders did not place big emphasis on dimensional differences and showed similar preferences over 2D and 3D [11].

Also according to the research analyzing the difference of the audience preference by age and gender to the realistic or unrealistic story telling of a 3D animation, the elementary school students preferred the unrealistic story telling while the college students preferred the realistic ones. This shows a remarkable difference in the recognition of a reality and story depending upon the ages. But there was no meaningful difference observed in the realistic or unrealistic story telling depending upon the gender [12]. At the same time there exists a research on the difference depending upon the ages in the preference of animal and animal characters personified in the picture books [13].

Looking at additional results regarding gender, female users are more sensitive to intelligent agent's gender and prefer female intelligent agents. From a social perspective, these results might be due to the tendency for women to put more emphasis on social relationships, and their interest in build close relationships with a small number of other females. In conclusion, women are more sensitive to demographic characteristics than men, and this needs to be considered when conducting related re-search [14].

In research that compared preference and trust in face-shaped A.I. speakers, student group and elder group showed different levels of preference. Elders showed constantly increased level of preference as the resemblance to human face increased, while students showed maximum preference when the speaker had mid-to-high level of resemblance to human face. There were no significant differences found according to gender. On the contrary, a research suggests that some elders felt fear when faced with overly humanlike social robots [10].

\section{METHOD}

This research analyzed differences in preference for visual-realness of intelligent agents (in autonomous driving cars) be-tween users of different age groups, driving frequencies, gender, and driving purpose. Thirty-four participants in their 20's and 30's participated, and sixteen of these were men, while 18 of these were women. Age groups consisted of 23 participants in 25-29 years old age group (67.6\%), 8 participants in 30-34 years old age group (23.5\%), 2 participants in 20-24 years old age group (5.9\%), and 1 participant in 35-39 years old age group (2.9\%). The age of participants ranges from 20's to 30 's, who are considered as main AI service users. Other age groups are excluded due to temporal and financial constraints.

The participants all had relatively short driving history, with $35.3 \%$ of the participants having driven 1 to 5 years, and $26.5 \%$ of the participants having driven less than 6 months. Overall, $76.5 \%$ of the participants have less than 5 years of driving experience. In terms of driving frequencies, $35.3 \%$ responded they only drive on weekends, $23.5 \%$ responded once or twice a week, $20.6 \%$ responded they drive 5 to 6 times a week, $14.7 \%$ responded every day, and 5.9\% responded they drive 3 to 4 times a week.

The following table is a summary of demographics of the participants. 
Table I. Participant Demographics Summary

\begin{tabular}{|c|c|c|c|}
\hline \multicolumn{2}{|c|}{ Category } & $\begin{array}{c}\text { Number } \\
\text { of users }\end{array}$ & Percent $(\%)$ \\
\hline \multicolumn{2}{|r|}{ All } & 34 & 100 \\
\hline \multirow{2}{*}{ Gender } & Male & 16 & 47.1 \\
\hline & Female & 18 & 52.9 \\
\hline \multirow{4}{*}{ Age Group } & $20 \sim 24$ & 2 & 5.9 \\
\hline & $25 \sim 29$ & 23 & 67.6 \\
\hline & $30 \sim 34$ & 8 & 23.5 \\
\hline & $35 \sim 39$ & 1 & 2.9 \\
\hline \multirow{5}{*}{$\begin{array}{c}\text { Driving } \\
\text { Experience }\end{array}$} & $\begin{array}{c}\text { Less than } 6 \\
\text { months }\end{array}$ & 9 & 26.5 \\
\hline & Less than 1 year & 5 & 14.7 \\
\hline & $\begin{array}{c}\text { More than } 1 \\
\text { year, less than } 5 \\
\text { years }\end{array}$ & 12 & 35.3 \\
\hline & $\begin{array}{c}\text { More than } 5 \\
\text { years, less than } \\
10 \text { years }\end{array}$ & 6 & 17.6 \\
\hline & $\begin{array}{c}\text { More than } 10 \\
\text { years }\end{array}$ & 2 & 5.9 \\
\hline \multirow{5}{*}{$\begin{array}{c}\text { Driving } \\
\text { Frequency }\end{array}$} & Everyday & 5 & 14.7 \\
\hline & $\begin{array}{l}5 \sim 6 \text { times } \\
\text { weekly }\end{array}$ & 7 & 20.6 \\
\hline & $\begin{array}{l}3 \sim 4 \text { times } \\
\text { weekly }\end{array}$ & 2 & 5.9 \\
\hline & $\begin{array}{l}1 \sim 2 \text { times } \\
\text { weekly }\end{array}$ & 8 & 23.5 \\
\hline & $\begin{array}{c}\text { Only on } \\
\text { weekends }\end{array}$ & 12 & 35.3 \\
\hline \multirow{5}{*}{$\begin{array}{c}\text { Purpose of } \\
\text { Driving }\end{array}$} & $\begin{array}{l}\text { Commute to } \\
\text { Work }\end{array}$ & 16 & 47.1 \\
\hline & $\begin{array}{c}\text { Short distance } \\
\text { travelling } \\
\text { (supermarket, } \\
\text { department store, } \\
\text { taking children } \\
\text { to school and } \\
\text { back) }\end{array}$ & 5 & 14.7 \\
\hline & $\begin{array}{l}\text { Family trip and } \\
\text { long distance trip }\end{array}$ & 5 & 14.7 \\
\hline & $\begin{array}{l}\text { Business and } \\
\text { sales }\end{array}$ & 2 & 5.9 \\
\hline & $\begin{array}{c}\text { Weekend } \\
\text { hobbies or } \\
\text { leisure activities }\end{array}$ & 6 & 17.6 \\
\hline
\end{tabular}

We used online surveys to collect data on users' preference over human and companion animal intelligent agents' gender, visual realness and resemblance to humans, and dimensions(2D/3D). The participants rated such preferences based on the Likert scale $(1=$ very unsatisfactory $/ 2=$ unsatisfactory $/ 3=$ normal $/ 4=$ satisfactory $/ 5=$ very satisfactory). We also did T-test and analysis of variance on preferences for variables such as demographical characteristics (gender, age group), driving frequency, driving purposes - based on variable types (categorical, continuous). This research aims to 
analyze preferences for gender or level of anthropomorphism in intelligent agents; thus, we considered intelligent agents with high visual resemblance to humans (realness) in high dimension (3D) to be more anthropomorphic.

Firstly, we used 6 questions in the survey to identify the preferences for human and companion animal intelligent agents. Given are questions on sex and the level of anthropomorphism of human intelligent agents and images used in each question in Table II. Respondents show their preference on each question based on Likert 5 scale.

Table II. Questionnaire on the human agents

\begin{tabular}{|c|c|c|}
\hline $\begin{array}{c}\text { Categor } \\
\mathrm{y}\end{array}$ & Contents of Questionnaire & Given Images \\
\hline \multirow{2}{*}{ Gender } & $\begin{array}{l}\text { 1. the preference } \\
\text { degree on the } \\
\text { male type agent }\end{array}$ & \\
\hline & $\begin{array}{l}\text { 2. Indicate the } \\
\text { preference } \\
\text { degree on the } \\
\text { female type } \\
\text { agent }\end{array}$ & \\
\hline \multirow{4}{*}{$\begin{array}{l}\text { Reality } \\
\text { or Not }\end{array}$} & $\begin{array}{l}\text { 3. Indicate the } \\
\text { preference } \\
\text { degree on the } \\
\text { agent of high } \\
\text { visual reality }\end{array}$ & \\
\hline & $\begin{array}{l}\text { 4. Indicate the } \\
\text { preference } \\
\text { degree on the } \\
\text { high degree of } \\
\text { visual } \\
\text { abstractness }\end{array}$ & \\
\hline & $\begin{array}{l}\text { 5. Indicate the } \\
\text { preference } \\
\text { degree on the } \\
\text { 3D expressed } \\
\text { agent }\end{array}$ & \\
\hline & $\begin{array}{l}\text { 6. Indicate the } \\
\text { preference } \\
\text { degree on the } \\
\text { 2D expressed } \\
\text { agent }\end{array}$ & \\
\hline
\end{tabular}

This research analyzes respondent's preference for sex and anthropomorphism of intelligent agents with question 1 and 2 in Gender section and question 3 and 5 in Reality or Not section as dependent variables. As for question 3 and 5 of Reality or Not section both estimate the level of anthropomorphism, factor analysis is adopted for analyzing correlation between two variables.

The aim of the factor analysis is to reveal any latent variables that cause the manifest variables to covary. After conducting factor analysis about factors in the questions, questions 3 and 5 had correlation value of 0.67>0.6. Therefore, we analyzed the average of the users' preference level for questions 3 and 5 .

Table III below shows questions on sex and the level of anthropomorphism of human intelligent agents and images used in each question. Respondents show their preference on each question based on Likert 5 scale. 
Table III. Questionnaire related to the pet animal type of agents

\begin{tabular}{|c|c|c|}
\hline Category & Contents of Questionnaire & Given images \\
\hline \multirow{2}{*}{ Gender } & 1. Pet agent with male shape & \\
\hline & $\begin{array}{l}\text { 2. Pet agent with female } \\
\text { shape }\end{array}$ & \\
\hline \multirow{4}{*}{$\begin{array}{l}\text { Reality } \\
\text { or Not }\end{array}$} & $\begin{array}{l}\text { 3. Agent with higher visual } \\
\text { reality }\end{array}$ & \\
\hline & $\begin{array}{l}\text { 4. Agent with lower visual } \\
\text { reality }\end{array}$ & \\
\hline & $\begin{array}{l}\text { 5. Pet shaped agent ex } \\
\text { pressed in 3D }\end{array}$ & \\
\hline & $\begin{array}{l}\text { 6. Pet shaped agent ex } \\
\text { pressed in } 2 \mathrm{D}\end{array}$ & \\
\hline
\end{tabular}

Similar to above, questions regarding companion animal intelligent agent had similar correlation value after factor analysis. Questions 3 and 5 had correlation value of 0.6. Thus, to examine if the preference level about real-looking intelligent agent is relevant and significant, we averaged the user's preference level for questions 3 and 5 and analyzed this value.

\section{RESULTS}

\subsection{AGE GROUPS AND DRIVING FREQUENCIES}

Firstly, we looked at how the preference for gender of intelligent agent differed depending on age groups. Previous studies show that users usually prefer female intelligent agents; women have been shown to consider same-sex kinship and ties very important. Our research agrees with the previous research, showing that female intelligent agents are preferred. Figure 2 shows how both age groups(20's and 30's) favor female intelligent agents. In terms of companion animal gender preference, users in the 20's age group favored female agent, while users in the 30's age group favored male intelligent agents (3.11 for male vs. 2.89 for female). 


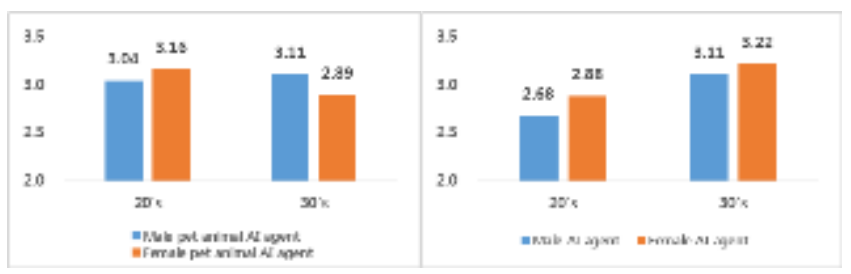

Fig. 2 Differences in Preference for Human and Companion Animal Intel-ligent Agents Between Age Groups

Previous studies on drivers' preference for sex of intelligent agent indicated there is preference for female intelligent agents. Figure 2 shows that while all age groups follow existing inclination, the age group of 30's only shows the opposite. This result leads to the deduction that respondents of their 30's are hard to be fully involved emotionally in animal intelligent agents enough to assign sex to them, which is a far cry from how those of their 20's respond. Actually, Figure 3 proves that preference of the age group of their 30 's for anthropomorphism of AI Agent is higher than those of 20's, showing that 30's respondents put more emphasis on visual fidelity than 20 's.

On the other side, analyzing the differences between different age groups and users with different driving frequencies in terms of preferences for realistic-looking intelligent agents can be significant. Thus, this research analyzes this preference difference between different groups and variables.

Firstly, looking at the preference for intelligent agents with realistic visuals in different age groups, the older age group (30's) preferred more anthropomorphism (mean=3.39, standard deviation $=0.96)$ compared to the younger age group (20's) who preferred less anthropomorphism (mean=3.20, standard deviation=0.99). This agrees with previous research showing that older age groups prefer more personified looking agents. However, the p-value for these two groups is $0.62>0.05$. For all comparisons, a $\mathrm{p}$-value of < 0.05 was considered statistically significant. Therefore, there doesn't seem to be any significant differences. On the other side, looking at the preference for visually realistic animal intelligent agents, the younger age group (20's) showed higher preference (mean=2.64, standard deviation=1.11) compared to older age group (30's) who showed lower preference $($ mean $=2.06$, standard deviation $=0.85$ ), which is the opposite compared to level of anthropomorphism [Figure 3].

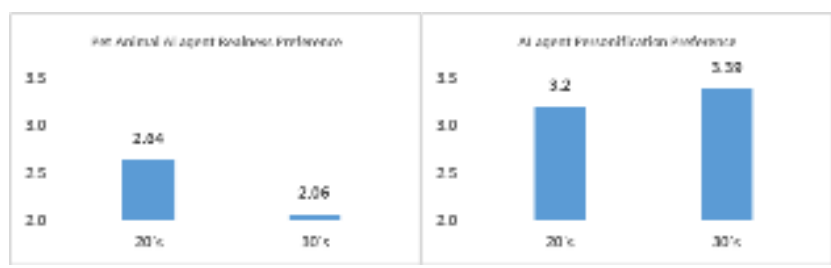

Fig. 3 Personification Preference for AI Agent and Realness Preference for Pet animal AI Agent

Looking at driving frequencies and preferences for level of anthropomorphism, people who answered they drove every day (mean $=3.50$, standard deviation=0.90) and people who drove 5 to 6 times a week (mean $=3.50$, standard deviation $=0.70$ ) had the highest preference. This was followed by people who drove 3 to 4 times a week (mean=3.14, standard deviation=0.70), and people who drove 1 to 2 times a week (mean=2.96, standard deviation=1.20). Overall, one could say that people who drive more preferred higher level of anthropomorphism in their intelligent agents. But the p-value between different groups was $0.67>0.05$, and did not show a significant difference. On the contrary, the preference for companion animal intelligent agent's visual realness did not 
have notable relationships with driving frequencies, and the $p$-value, $0.43>0.05$, between different groups did not show any significance, either Figure 4.

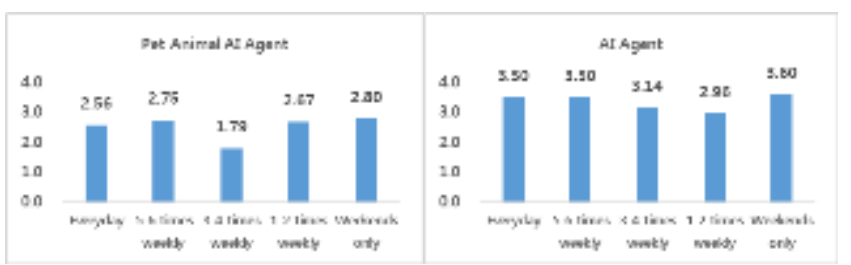

Fig. 4 Preference Levels for Visually Realistic Intelligence Agent and Companion Animals Depending on Driving Frequency

\subsection{GENDER AND DRIVING PURPOSE}

Gender and driving purpose also had impacts on preference levels. Difference in the agent's preference by genders as per the user genders were as follows. Male preferred female for human agent, female for pet types so in both cases showed trends of preference in the female character agents. Females preferred as opposite sex the male as human agents, but for animal intelligent agents the preference of female and male agents were identical Figure 5. This result may be applied the previous research analysis that users are greatly affected by the attractions when choosing the artificial secretary.

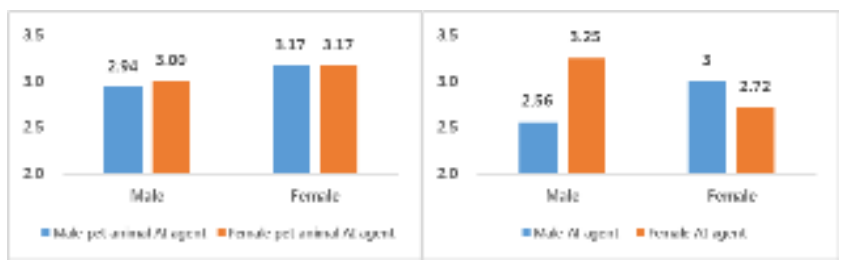

Fig. 5 Difference in the preference of human and pet agents according to gender

Looking at gender differences between male and female users in preference levels for different levels of anthropomorphism in intelligent agents, female users (mean $=3.33$, standard deviation=0.97) had a higher preference for increased level of anthropomorphism in intelligent agents compared to male users (mean $=3.16$, standard deviation=1.00). The p-value was $0.60>0.05$, with no significance in difference. On the contrary, the preference levels for visually-realistic companion animal intelligent agents was higher in male users (mean=2.59, standard deviation=1.07) than female users (mean $=2.39$, standard deviation $=1.09$ ). The $\mathrm{p}$-value was $0.59>0.05$, and did not show any significance in difference Figure 6.

This result shows that male and female respondents' perspectives toward intelligent agents are different. That is, in the case of female respondents, they tend to care for specific factors of intelligent agents' appearance so that they prefer more realistic characters in the case of human agents, while this tendency does not reflect the preference for animal intelligent agents' character [15].

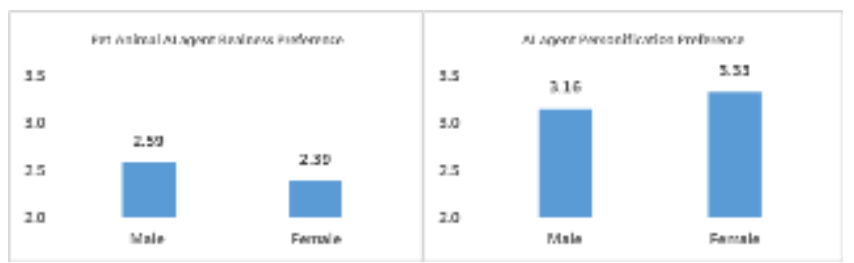

Fig. 6 Personification Preference for AI Agent and Realness Preference for Pet animal AI Agent Depending on Gender 
While it was hard to find significant different in results among age groups with driving frequencies, we were able to find significant results groups with different driving purposes. We con-ducted analysis on the 5 different driving purposes:

1. commute to work and school (4.25)

2. long distance trips (4.10)

3. short distance travelling (3.19)

4. hobby and leisure purposes (3.30)

5. business and sales trips (2.93)

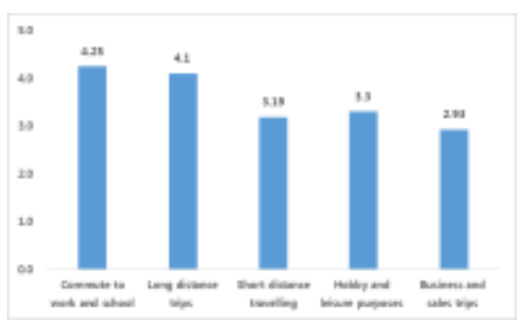

Fig. 7 Differences in Preference for Human AI Agents's Personification Depending on Driving purposes

The p-value was $0.013<0.05$, and showed that the difference in driving purposes led to significant difference in preference levels for anthropomorphism levels. This shows that certain life-style of different users may lead to preference for more anthropomorphism. Furthermore, we additionally analyzed preference levels for visually-realistic companion animal intelligent agents, but found no significant different with $\mathrm{p}$-value of $0.507>0.05$.

\section{CONCLUSION}

After Apple's Siri appeared on the market in 2011, the intelligent agent market has exponentially grown. The cooperation between IT corporations and car companies have consistently aimed to incorporate intelligent agent technology into cars. As related technologies have continually developed, the functionality of the agents have come very close to that of humans. As such, there is naturally a lot of debate about whether one should consider the intelligent agents to be simple machines or substitutes for humans. Furthermore, as the agents need to work physically close to the users, the visual aspect of the agents and the preference levels of users for such visuals must be a studied area. Thus, this research studied users' preference levels for human and companion animal intelligent agents' genders and visual-realness. Further analysis showed how preference levels differed between groups of different demographical characteristics (gender, age group), driving frequency, and driving purposes.

Looking at preference levels for different genders between two age groups (20's and 30 's), all groups preferred female agents. However, looking at preference levels for different genders in companion animal intelligent agents, users in their 20's had higher preference for female agents, while users in their 30's ha higher preference for male agents.

Looking at preference levels for anthropomorphized intelligent agents between different age groups, users in their 30's preferred more anthropomorphized agents (mean=3.39, standard deviation=0.96) compared to users in their 20's (mean=3.20, standard deviation=0.99). Previous studies have shown that higher age groups prefer human-like agents, and this research shows same results. However, the p-value of the two 
groups' preference level is $0.62>0.05$, and shows no significant difference. On the other hand, companion animal intelligent agents with high visual realness showed opposite results; people in their 20's preferred agents with high visual realness (mean=2.64, standard deviation=1.11) compared to people in their 30's (mean=2.06, standard deviation=0.85).

Looking at preference levels for anthropomorphized intelligent agents between groups with different driving frequencies, groups with higher driving frequency had higher preference level for higher level of anthropomorphism in human-like agents. But, there was no significant relationship between level of anthropomorphism and companion animal intelligent agents.

Furthermore, looking at preference levels for anthropomorphized intelligent agents between different gender groups, female users preferred more anthropomorphized agents compared to males. On the other hand, male respondents' preference for companion animal intelligent agents is higher than that of female agents. As for human intelligent agents, both male and female respondents prefer intelligent agents with opposite sex. Yet, in case of companion animal intelligent agents, both of them prefer female animal intelligent agents.

Lastly, looking at driving purposes, the difference in driving purposes led to significant differences in preference levels of anthropomorphized intelligent agents. In particular, respondents who use cars for the purpose of commutation show relatively higher preference than other types of respondents. However, in cases of companion animal intelligent agents, there was no significant differences in groups of different genders or driving purposes.

The significance of this research lies in the fact preferences for sex, realness, and personification of human and companion animal intelligent agents are analyzed in the perspective of user interface. Compared to the previous studies, this research analyzes preference for intelligent agents of self-driving cars. Moreover, it shows that preference tendency for intelligent agents based on sex and age group of respondents is also found in preference for intelligent agents of self-driving cars.

\section{ACKNOWLEDGMENTS}

This work was supported by the Technology Innovation Program (or Industrial Strategic Technology Development Program-Core Technology Development Program for Automotive Indus-try) (10077311, Development of integrated control system based on multi-core processor with multi-OS for integration of in-vehicle displays) funded By the Ministry of Trade, Industry \& Energy (MOTIE, Korea).

This material is based upon work supported by the Ministry of Trade, Industry \& Energy (MOTIE, Korea) under Industrial Technology Innovation Program. No.10060517, 'Development of an user-centered product design support system based on cognitive and affective information'.

\section{REFERENCES}

[1] G. Lugano, "Virtual Assistants and Self-Driving Cars: To what extent is Artificial Intelligence needed in Next-Generation Autonomous Vehicles?", Proceedings of 15th International Conference on ITS Telecommunications (ITST), Warsaw, Poland, (2017) May 29-31.

[2] H. M. Kim, "KB knowledge vitamin: the development in AI technology and evolution in virtual agent service", (2016), 16, 1-9.

[3] H. T. Yang and D. B. Kim, "Trend in intelligent personal assistant market and forecasting domestic industry impact", Science \& Technology Policy, (2017), 35, 1-30.

[4] J. Y. Kim, "The Influence of Anthropomorphised Message on Donation Intention: The Construal Level Effect”, The Korean Journal of Consumer and Advertising Psychology, (2014), 15, 649-666.

[5] K. L. Nowak and F. Biocca, "The Effect of the Agency and Anthropomorphism on Users' Sense of Telepresence, Compresence, and Social Presence in Virtual Environments, Presence 12, (2003), 481494. 
[6] M. Kramer, R. Yaghoubzadeh, S. Kopp, K. Pitsch, "A conversational virtual human as autonomous assistant for elderly and cognitively impaired users?", Proceeding of INFORMATIK 2013, Koblenz, Germany, (2013) September 16-20.

[7] M. S. B. Mimoun, I. Poncin, M. Garnier, "Case study—Embodied virtual agents: Analysis on reasons for failure", Journal of Retailing and Consumer Service, (2012), 19, 605-612.

[8] https://simple.wikipedia.org/wiki/Uncanny_valley.

[9] V. Groom, C. Nass, T. Chen, A, Nielsen, J. K. Scarborough, E. Robles, "Evaluating the effects of behavioral realism in embodied agents", International Journal Human-Computer Studies, (2009), 67, $842-849$.

[10] S. J. Oh, J. H. Hwang, J. H, Yew, S.W. Hahn, "Age differences of preference for humanoid AI speakers", Korean Journal of Cognitive Science, (2018), 29, 1-16.

[11] C. Strabmann and N. C. Kramer, "A categorization of virtual agent appearances and a qualitative study on age-related user preferences", International Virtual Agents 10498, (2017), 413-420.

[12] H. H. Shin and H. H. Kim, "Analysis of Audience Preference for Realistic or Non-realistic Expression Focus on Rendering Technique in 3D Animation", Journal of Digital Design, (2013), 13, 611-620.

[13] H. J. Choi and J. K. Paik, "The research on the preference about anthropomorphio animal oharaoter's visual communication of the picture book", Journal of Integrated Design Research, (2009), 8, 129-141.

[14] J. A. Payne, A. Szymkowiak, G. Johnson, P. Robertson, R. Henderson, "Beyond Embodiment and Social Presence: Preferences for Virtual Assistant Gender and Clothing Style", Proceedings of International Society for Presence Research Annual Conference, Philadelphia, United States, (2012) October 24-26.

[15] I. S. Park, "A Study on Responses of Consumers to Expression Types of Character Design - Focus on The Difference between The Sexes", Journal of Brand Design Association of Korea, (2017), 15, 4-14. 
International Journal of Advanced Science and Technology Vol.124 (2019) 